\title{
Adaptation, compromise, and constraint: the development, morphometrics, and behavioral basis of a fighter-flier polymorphism in male Hoplothrips karnyi (Insecta: Thysanoptera)
}

\author{
B.J. Crespi \\ Museum of Zoology and Department of Biology, University of Michigan, Ann Arbor, MI 48109-1079, USA
}

Received November 20, 1987 / Accepted April 17, 1988

Summary. Males of the colonial, wing-polymorphic thrips Hoplothrips karnyi (Hood) fight each other with their forelegs in defense of communal female oviposition areas. In this study, males were reared individually under varying conditions of food deprivation to investigate the developmental cues used in morph determination and the relationships between wing morph, developmental time in each instar, propupal weight, and five adult morphological characters associated with fighting ability and dispersal ability. Males deprived of food for five days midway through the second (final) larval instar had smaller propupal weights and were more likely to develop wings than males deprived of food in the first instar or control males. However, the mean propupal weight of all males that developed wings was not significantly less than that of wingless males. Wing morph of female parents had no measurable effect on this character in the offspring. Wingless males possess relatively larger fore-femora and prothoraces than do winged males, but winged males possess relatively larger pterothoraces (Fig. 1). Behavioral observations of wingless and winged males of similar weight as propupae showed that wingless males won fights and became dominant in oviposition areas. Thus, a trade-off exists between characters associated with male fighting and dispersal ability. The cost of wings, in terms of fore-femora size and prothorax size, increased with propupal weight. Wingless males that developed in the experimental treatment that produced a high proportion of winged males were relatively small in size, and were intermediate in body shape with respect to winged males and other wingless males (Fig. 2). This shape intermediacy indicates that there may be developmental constraints on alternative tactics of resource allocation. Total developmental time varied between wing morphs, but was not corre- lated with propupal weight or adult morphological characters of winged or wingless males. For wingless males that developed in the treatment that produced a high proportion of winged males, adult morphological characters were negatively correlated with the duration of the second instar. This correlation suggests that the development of small wingless males involves a compromise between the benefits of large adult size and the costs of prolonging the second instar to increase the probability of becoming larger.

\section{Introduction}

Discontinuous morphological variation within species is usually construed as reflecting adaptive responses to selection pressures that vary in time or space (Huxley 1955; Mather 1955; Levins 1968; Clark 1976; Lively 1986). The maintenance of more than one morph implies that the different morphs are specialized, genetically and/or phenotypically, to particular ecological or social environments. Such alternative specializations are important in studies on the maintenance of morphological and behavioral variability (Cade 1980; Thornhill and Alcock 1983; Barnard 1984; Caro and Bateson 1986), as well as in understanding longterm evolutionary trends, such as speciation (WestEberhard 1983) and adaptive radiation (Hamilton 1978). However, selective trade-offs are often difficult to identify and measure, and the extent to which the alternatives are subject to developmental constraints is generally unknown (Maynard Smith et al. 1985). Here I present experimental, morphometric, and behavioral evidence that wing polymorphism in males of a colonial thrips, Hoplothrips karnyi (Hood), is associated with a trade-off 
between male fighting and dispersal ability, and that the trade-off may be affected by developmental constraints.

Among non-social insects, discontinuous variation takes two primary forms: dispersal polymorphism and male dimorphism. Dispersal polymorphisms comprise variation in wing and flight muscle development, and are common among female insects (Gupta 1979). Wingless females usually exhibit greater fecundity or earlier onset of reproduction than do winged females, at the expense of being unable to colonize new habitats (Harrison 1980; Zera 1984; Roff 1986a, but see Taylor 1978, 1981; Ritchie et al. 1987). In some species, wing morph is under simple genetic control or subject to polygenic influences (Langor and Larson 1983; Zera et al. 1983; Roff 1986b; Solbreck 1986; Briceno and Eberhard 1987; Messina 1987). However, in most species morph determination is cued primarily by environmental factors, such as population density, photoperiod or food quality. These environmental factors suggest that wing polymorphisms are maintained through variation in the costs and benefits of dispersal (Harrison 1980; Roff 1986a).

In contrast to wing polymorphisms among female insects, male structural dimorphisms are rare and usually involve characters associated with male fighting (Woodring 1969; Shillito 1971; Dominey 1980; Eberhard 1980; Cowan 1984; Goldsmith 1985, 1987; Gross 1985), searching for mates (Day 1984), or both fighting and dispersal. For example, in agaonid wasps (Hamilton 1979), scarab beetles (Eberhard 1980, 1982; Siva-Jothy 1987), ants (Kinomura and Yamauchi 1987), and, apparently, halictid bees (Houston 1970), two forms of males exist: "fighter" males, possessing well-developed weaponry and limited dispersal ability, and poorly armed but more mobile "fliers." Despite widespread interest in the origin and maintenance of alternative male reproductive tactics (Cade 1980; Dominey 1984), few studies have addressed the developmental basis or ecological correlates of male dimorphism (Kuhl 1928; Woodring 1969; Hamilton 1979; Timms et al. 1981 a, b, 1981; Eberhard 1982).

Many species of mycophagous thrips in the suborder Tubulifera exhibit wing dimorphism and sexual dimorphism in foreleg size and shape (Stannard 1968; Ananthakrishnan 1979, 1984) that have been interpreted as polymorphisms associated with male fighting (Hamilton 1979; Crespi 1986a, b, 1988). Large males often possess greatly developed forelegs, whereas smaller males have less developed forelegs similar in size to those of females. Al- though males of a particular wing morph vary continuously in body and foreleg size (Hood 1935, 1937; Ananthakrishnan 1967, 1970; Kiester and Strates 1984), several authors (Stannard 1957; Ananthakrishnan 1968; Mound 1970,1972) have noted that males with large forelegs tend to be wingless or short-winged. Crespi $(1986 \mathrm{a} ; 1988)$ showed, for Hoplothrips pedicularus and H. karnyi, that although males with the largest forelegs were invariably wingless, winged and wingless males overlap considerably in foreleg size. In $H$. pedicularius and $H$. karnyi, males fight each other with their forelegs and abdomens in territorial defense of communal female oviposition sites, and large males win (Crespi 1986a, 1988). Consequently, foreleg and wing variation may have considerable effects on male reproductive success.

This study was designed to investigate the development, morphometrics, and behavioral basis of wing dimorphism and foreleg variation in Hoplothrips karnyi, a mycophagous, colonial, wing-polymorphic thrips. The study has three purposes: (1) uncovering the influences of pupal weight, food deprivation during each instar, and heredity on wing morph determination, (2) describing, for winged and wingless males, the morphometric relationships among characters associated with male fighting and dispersal ability, and the relationships between the experimental treatments, developmental time in each instar, and morphology; and (3) evaluating the relationship between male wing morph and fighting success. Analyses of variation in patterns of male size, shape, developmental time, and behavior are designed to indicate the extent to which male phenotypes can be considered adaptive responses to variation in developmental conditions.

\section{Methods}

\section{Biology and development of thrips}

Thrips are minute haplodiploid insects with an unusual form of development, termed remetaboly, intermediate between holometaboly (complete metamorphosis) and hemimetaboly (partial metamorphosis) (Heming 1973, 1975). Tubuliferan thrips have two larval instars, designated here as L1 and L2, a propupal instar, designated as PP, and two pupal instars, designated as P1 and P2. Larvae coexist with adults and exhibit similar feeding habits. Propupae and pupae do not feed and are inactive, but capable of movement if disturbed. In individuals destined to develop wings, wing sheaths evaginate in the first pupal instar and are retained in the second pupal instar. Developmental studies have shown that the propupal and pupal instars involve considerable histolysis and internal reorganization, processes characteristic of true pupal stages (Davies 1969; Heming 1970, 1973, 1975). 
Hoplothrips karnyi is a black thrips $3-4 \mathrm{~mm}$ long that lives in colonies on shelf fungi and feeds on mycelium. Colonies vary in size from a few individuals to hundreds of larvae, pupae and adults in close proximity (Graves 1960), and may persist for years (Crespi pers. obs.). In Michigan, this species is multivoltine and reproduces whenever the fungi on which it feeds are growing (Crespi pers. obs.). The systematic position of $H$. karnyi is uncertain; this thrips keys to Hoplothrips beachae (Hinds) in Stannard (1968), but actually belongs to the H. karnyi (Hood) species complex, which comprises "a number of closely related and ill-defined species from North America and Europe" (Mound and Palmer pers. comm.). Voucher specimens from this study have been deposited in the University of Michigan Museum of Zoology insect collection.

A detailed account of the sexual and social behavior of Hoplothrips karnyi is presented elsewhere (Crespi 1988); relevant details are summarized here. Female $H$. karnyi oviposit onto communal egg masses in crevices under bark. Males fight each other with their forelegs and abdomens in territorial de fense of egg mass areas, mating with females that come to oviposit. Large, wingless males win fights and defend egg mass areas, whereas smaller wingless males and winged males mate with females away from egg mass areas and attempt to "sneak" matings with females in egg mass areas. In the absence of large wingless males, small wingless males and winged males fight and defend egg mass areas. Observation and inference of takeovers shows that individual males can switch between the "guarding" and "sneak" strategies. Guarding an egg mass dramatically increases a male's success at mating with ovipositing females; in four laboratory colonies consisting of 6 males and 8-10 females, males defending egg mass areas secured about $80 \%$ of the matings that precede ovipositions (Crespi 1988).

\section{Collection and rearing}

An overwintering colony of several hundred adult and larval Hoplothrips karnyi was collected on 10 December 1983 on a $\log$ of beech (Fagus grandifolia) wood infested with Polystictus versicolor fungus in Warren Woods, a virgin beech-maple forest in Berrien County, Michigan. The log containing the colony was kept at $-2^{\circ} \mathrm{C}$ until March, when several dozen secondinstar larvae were removed, reared on small pieces of fungusinfested wood at $22^{\circ} \mathrm{C}$, sexed, and scored for wing morph. Seven brachypterous females and 11 macropterous females, all virgin, were allowed to feed until fully gravid. (Since thrips are haplodiploid, virgin females produce only male eggs). Eggs from each female were removed daily for 14 days and transferred to empty petri dishes containing a few drops of water. Hatching, which took place 12-14 days after oviposition, was monitored daily. Each newly-hatched larva was put alone in a $50 \times 9 \mathrm{~mm}$ tight-sealing petri dish containing pieces of fungusinfested beech wood from its natal colony, such that the larva inhabited a $0.1-1 \mathrm{~mm}$ space between the wood and plexiglass. The wood was kept moist with distilled water.

Larvae and pupae were reared individually at $22^{\circ} \mathrm{C}$ on a 16L:8D light cycle. Larvae were subjected to five treatments, involving food deprivation, by transfer to petri dishes containing only a few drops of distilled water, for two or five days beginning on the fourth day after hatching (treatments L12 and L15), or for two, five, or eight days beginning on the fourth day after molting to the second instar (treatments L22, L25 and L28). These treatments were designed to mimic natural variation in fungal growth during larval development. Control males (designated as CON) were not transferred or deprived of food. Larvae from each female were randomly assigned to treatments, such that each female had roughly equal numbers of progeny in each group. Transfers to empty petri dishes were conducted between 1100 and $1300 \mathrm{~h}$ daily, and larvae and pupae were checked twice daily (between 830-1130 and 1530-1930 h) to monitor their molts. Half (22 of 44) of the L25 males and $86 \%$ ( 43 of 50 ) of the L28 males molted to the propupal stage during the food deprivation treatment; as a result, L25 and L28 males had been without food as larvae for an average of $4.84 \pm 0.37$ and $5.60 \pm 1.10$ days respectively before molting. Because these two treatments were nearly identical, they were pooled for the analysis and designated as L25.

Developmental times in each instar were calculated using the midpoints of the intervals between the time at which an individual molted to a new instar and the last time prior to this that the individual was checked. This method resulted in non-normal distributions of developmental times, so non-parametric tests were used for these data. In the $24 \mathrm{~h}$ following the molt to the propupal stage, individuals were weighed to the nearest $0.001 \mathrm{mg}$ on a Cahn electrobalance. Since propupae and pupae do not feed, and at this moult most of the body material is fat-body (Priesner 1960), propupal weight should be an accurate measure of food resources accrued as larvae.

Adults were scored for wing morph (brachypterous or macropterous, referred to here simply as wingless and winged). Fore-femoral length, prothorax length, prothorax width, pterothorax length, and pterothorax width were measured to the nearest $0.001 \mathrm{~mm}$ with a LASICO movable hairline micrometer on a WILD M8 microscope at 50-fold magnification. Thoracic characters were measured dorsally; prothorax width and pterothorax width were measured posteriorly and anteriorly respectively, and prothorax length and pterothorax length were measured along the dorsal midline. In thrips, the prothorax contains muscles for the forelegs and the pterothorax contains the flight muscles (Priesner 1960; Mickoleit 1961).

\section{Field collection and measurement}

On 6 and 12 June 1987, several hundred adults and pupae were collected from a colony of Hoplothrips karnyi inhabiting a log infested with Polystictus versicolor fungus in Livingston County, Michigan. The pupae were allowed to eclose, and the five morphological characters described above were measured on 14 winged males and 24 wingless males. These measurements were taken to determine if the range and nature of morphological variation was similar in the field and in these experiments.

\section{Behavioral observations}

To assess the relative fighting abilities of wingless and winged males, behavioral observations were conducted in small laboratory colonies containing one wingless male, one winged male, 3-4 gravid females, and a small egg mass. Ten pairs of males were chosen so that their propupal weights, as estimated from the regressions of fore-femoral length on propupal weight (Fig. $1 \mathrm{a}$ ), were close to one another. The thrips were observed in a $5 \times 10 \mathrm{~mm}$ observation chamber, with a 1-2 $\mathrm{mm}$ space between fungus-infested wood and clear plastic. Males had not previously been exposed to females as adults. The two males were put into the observation chamber, and the colonies were observed periodically over the next several hours. The dominant male in the colony was recognized by his attacks on the other male, and the consistent avoidance by the subordinate male of his opponent. Each pair of males was observed only once. 
Table 1. Univariate differences between wingless and winged males in the laboratory. Propupal weight is given as $\mathrm{mg} \times 10^{3}$, and morphological data are given as $\mathrm{mm} \times 10^{3}$. Data are given $\pm 1 \mathrm{SD}$, and tests were performed on the log-transformed data

\begin{tabular}{lllllll}
\hline Morph & $\begin{array}{l}\text { Propupal } \\
\text { weight }\end{array}$ & $\begin{array}{l}\text { Fore-femoral } \\
\text { length }\end{array}$ & $\begin{array}{l}\text { Prothorax } \\
\text { length }\end{array}$ & $\begin{array}{l}\text { Prothorax } \\
\text { width }\end{array}$ & $\begin{array}{l}\text { Pterothorax } \\
\text { length }\end{array}$ & $\begin{array}{l}\text { Pterothorax } \\
\text { width }\end{array}$ \\
\hline Wingless $(n=226)$ & $332 \pm 95$ & $477 \pm 96$ & $358 \pm 62$ & $543 \pm 69$ & $295 \pm 29$ & $540 \pm 63$ \\
Winged $(n=41)$ & $309 \pm 68$ & $338 \pm 47$ & $282 \pm 35$ & $476 \pm 41$ & $384 \pm 38$ & $532 \pm 46$ \\
$t$ & 1.48 & $8.88 * * *$ & $7.49 * * *$ & $5.72 * * *$ & $15.3 * * *$ & 0.62 \\
\hline
\end{tabular}

*** $P<0.001$

Table 2. Differences in weight and morphology among wingless males in the control and treatment groups. Propupal weight is given as $\mathrm{mg} \times 10^{3}$ and morphological data are given as $\mathrm{mm} \times 10^{3}$. Data are given $\pm 1 \mathrm{SD}$, and tests were performed on the log-transformed data

\begin{tabular}{|c|c|c|c|c|c|c|}
\hline & \multirow{2}{*}{$\begin{array}{l}\text { Control } \\
(n=53)\end{array}$} & \multicolumn{4}{|l|}{ Treatment } & \multirow[t]{2}{*}{$F$} \\
\hline & & $\mathbf{L 1 2}(n=31)$ & $\mathrm{L} 15(n=35)$ & $\mathrm{L} 22(n=39)$ & $\mathrm{L} 25(n=68)$ & \\
\hline Propupal weight & $370 \pm 86$ & $371 \pm 87$ & $356 \pm 81$ & $331 \pm 80$ & $274 \pm 95$ & $12.1 * * *$ \\
\hline Fore-femoral length & $512 \pm 74$ & $518 \pm 80$ & $505 \pm 74$ & $484 \pm 78$ & $411 \pm 104$ & $14.8^{* * * *}$ \\
\hline Prothorax length & $384 \pm 51$ & $386 \pm 50$ & $372 \pm 50$ & $361 \pm 49$ & $316 \pm 65$ & $15.3 * * *$ \\
\hline Prothorax width & $570 \pm 55$ & $575 \pm 59$ & $560 \pm 59$ & $544 \pm 55$ & $496 \pm 73$ & $15.1 * * *$ \\
\hline Pterothorax length & $299 \pm 26$ & $308 \pm 30$ & $299 \pm 23$ & $293 \pm 23$ & $284 \pm 33$ & $4.9^{* *}$ \\
\hline Pterothorax width & $564 \pm 50$ & $565 \pm 54$ & $555 \pm 49$ & $542 \pm 54$ & $500 \pm 67$ & $12.9 * * *$ \\
\hline
\end{tabular}

*** $P<0.001 ; * * P<0.01$

\section{Morphometric analysis}

To reduce scaling effects and preserve allometries, distance and weight data were transformed to natural logarithms (Jolicoeur 1963; Bookstein et al. 1985). The relationships between morphological characters and propupal weight were analyzed by analyses of covariance of the regressions of the characters on propupal weight for winged and wingless males. If the regressions of each morphological character on propupal weight for the different wing morphs did not overlap, or overlapped by only a few points (Fig. $1 \mathrm{a}-\mathrm{d}$ ), the regressions were considered to differ in elevation, and differences in slope were analyzed. Highly significant non-linearity of the regression of fore-femoral length on propupal weight for wingless males precluded covariance analysis in this case.

Principal components analysis (PCA) was conducted on the covariance matrices of the five adult morphological characters for analysis of size and shape variation among wing morphs and experimental treatments. Principal components analysis is a statistical method that reduces the dimensionality of a data set by representing it as several independent linear combinations of the original variables, which sequentially maximize the variance accounted for. Two methods were used for size-free shape discrimination between groups. First, principal component 2 (PC2) was "sheared" by regressing out the pooled within-group principal component 1 (PC1) (Humphries et al. 1981; Bookstein et al. 1985), and an ANOVA was conducted on the sheared PC2 scores. Second, because sheared PC2 was highly correlated with pterothorax length, adult body size (PC1) was also adjusted for using an analysis of covariance of pterothorax length on PC1. The former method (PCA) analyzes overall shape, whereas the latter method (ANCOVA) analyzes relative pterothorax size; the ANCOVA has the advantage of being simpler to interpret.

\section{Results}

\section{Wing morph determination}

Three hypotheses for wing morph determination were tested: (1) heredity (female parent's morph); (2) propupal weight (an indicator of food intake); and (3) the experimental treatments of food deprivation. The wing morph of female parents was not associated with the wing morph of their offspring; $21(17 \%)$ of 126 offspring of wingless females developed wings, versus $20(14 \%)$ of 141 offspring of winged females $(G=0.32 ; P>0.05)$. The average propual weight of males that became winged was not significantly different from that of wingless males (Table 1). A higher proportion of males developed wings under the L25 treatment of food deprivation for five days during the second larval instar $(28 \%, 26$ of 94), than in the control group $(5 \%, 3$ of 56$)$, the L12 treatment $(3 \%, 1$ of 32$)$, the L15 treatment $(15 \%, 6$ of 41$)$, or the L22 treatment $(11 \%, 5$ of 44$)(G=20.5, P<0.001)$.

\section{Univariate analysis}

Although winged and wingless males did not vary in propupal weight, wingless males had longer fore-femora, longer and wider prothoraces, and 
Table 3. Coefficients for the regressions of the characters on propupal weight, compared between wingless and winged males. Means are given $\pm 1 \mathrm{SD}$

\begin{tabular}{lllll}
\hline Morph & Prothorax length & Prothorax width & Pterothorax length & Pterothorax width \\
\hline Wingless $(n=226)$ & $0.548 \pm 0.054$ & $0.400 \pm 0.029$ & $0.225 \pm 0.068$ & $0.365 \pm 0.018$ \\
Winged $(n=41)$ & $0.438 \pm 0.074$ & $0.351 \pm 0.026$ & $0.323 \pm 0.070$ & $0.364 \pm 0.020$ \\
$F$ & $7.99^{* *}$ & $6.30^{*}$ & $4.32^{*}$ & 0.02 \\
\hline
\end{tabular}

${ }^{*} P<0.05 ;{ }^{* *} P<0.01$

shorter pterothoraces than did winged males (Table 1). Among wingless males, the treatment that generally caused males to become winged (L25) also produced a significant decrease in propupal weight (Table 2). For each character except pterothorax length, control males, males starved for two or five days in the first instar (L12 and L15), and males starved for 2 days in the second instar (L22) were larger than males starved for five days in the second instar (L25). For pterothorax length, L12 males were larger than L25 males, but CON, L15 and L22 males were not (Student-NewmanKeuls-tests, $P<0.05$ ).

\section{Bivariate analysis}

For a given propupal weight, wingless males had relatively large fore-femora and prothoraces, whereas winged males had relatively large pterothoraces (Fig. 1). Differences in the slopes of the regressions represent differences between the morphs in the relationship between propupal weight and investment in each character, or more specifically, differences in their allometries. Table 3 shows that winged and wingless males display significantly different slopes for the regressions of prothorax length, prothorax width, and pterothorax length on propupal weight; slopes for the prothorax are relatively steep for wingless males, and slopes for pterothorax length are relatively steep for winged males. The relationship between propupal weight and fore-femoral length is more complex. Although for winged males the regression is linear, for wingless males the regression exhibits highly significant non-linearity $(t=6.78, P<0.001$ for a quadratic term). As a result, the lightest winged and wingless males have similar fore-femoral lengths and the differences in fore-femoral length between morphs increases steeply until males reach a pre-pupal weight of about $0.300 \mathrm{mg}$. Above this weight the difference between morphs remains approximately constant.

\section{Multivariate analysis}

Principal component 1 (PC1) accounts for $84.6 \%$ of the variance in the data, and represents a general
Table 4. Principal components analysis on the five characters for laboratory males and field-collected males (in parentheses). Analyses were performed on the covariance matrices of the log-transformed data. Sheared PC2 loadings were calculated following Bookstein et al. (1985)

\begin{tabular}{lll}
\hline Character & $\begin{array}{l}\text { Principal } \\
\text { Component 1 }\end{array}$ & $\begin{array}{l}\text { Sheared Principal } \\
\text { Component 2 }\end{array}$ \\
\hline Fore-femoral length & $0.68(0.55)$ & $-0.09(-0.40)$ \\
Prothorax length & $0.54(0.63)$ & $-0.16(-0.55)$ \\
Prothorax width & $0.37(0.36)$ & $-0.03(0.28)$ \\
Pterothorax length & $0.09(0.24)$ & $0.91(0.56)$ \\
Pterothorax width & $0.30(0.33)$ & $0.20(0.25)$ \\
\hline
\end{tabular}

size factor (Table 4) (Wright 1968). The differences between the characters in their correlations with PC1 indicate strong allometry; in particular, large males have disproportionately large fore-femora and disproportionately small pterothoraces. Sheared principal component 2 (sheared PC2), accounting for $13.2 \%$ of the variance, represents a shape factor, or contrast between characters associated with fighting (the fore-femora and prothorax) and characters associated with dispersal (the pterothorax). This factor is correlated most strongly with pterothorax length. Sheared PC2 discriminates clearly between winged and wingless males; the difference between the morphs in sheared PC2 scores is highly significant $\left(F_{1,265}=\right.$ 1156.0, $P<0.0001$ ).

The hypothesis that wingless males which developed under the experimental treatment that produced a high proportion of winged males (L25) were intermediate in size-adjusted shape between winged males and other wingless males (males in the CON, L12, L15, and L22 treatments) was tested in two ways: by an ANOVA on sheared PC2 scores, and by an ANCOVA of PC1 and pterothorax length. The ANOVA was highly significant $\left(F_{2,264}=614.2, P<0.0001\right)$, and the sheared PC2 scores of wingless males that developed in the L25 treatment $(3.47 \pm 0.07, n=68)$ were intermediate between those of winged males $(3.83 \pm 0.07, n=41)$ and those of wingless males in the other treatments and the control males 

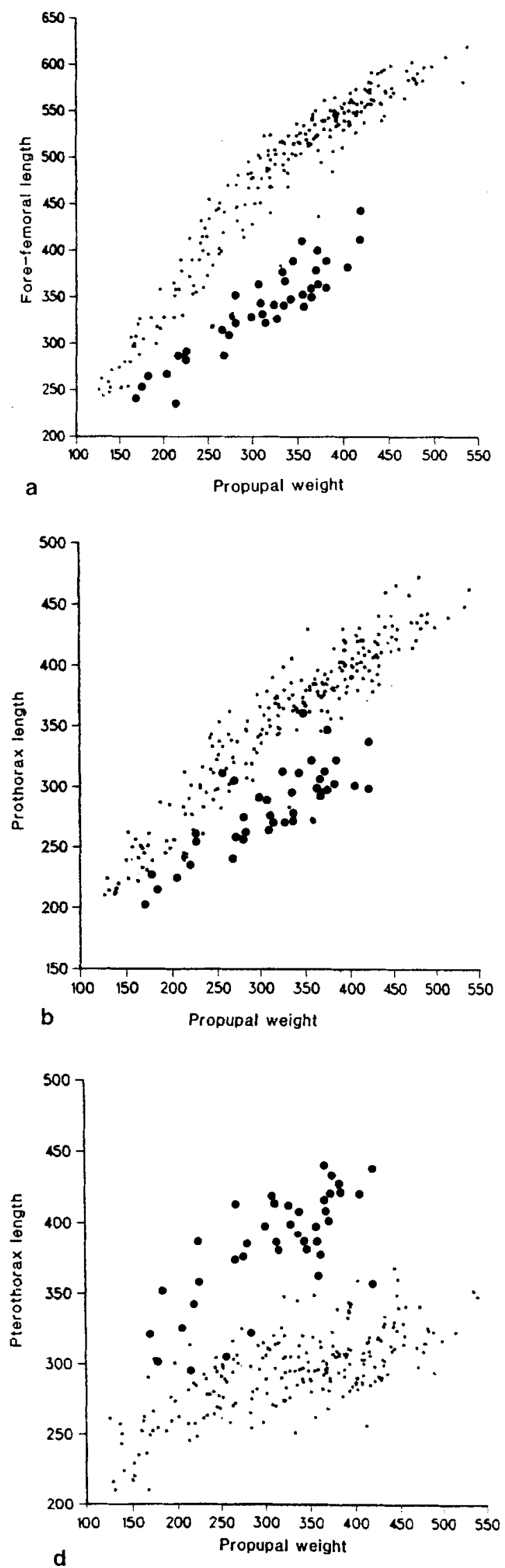

Fig. 1 a-e. Propupal weight versus male morphological characters in Hoplothrips karnyi, for: a) fore-femoral length; b) prothorax length; c) prothorax width; d) pterothorax length; e) pterothorax width. Large circles represent winged males and small circles represent wingless males. Wingless males have larger fore-femora and prothoraces and smaller pterothoraces than do winged males. Propupal weight is given in $\mathrm{mg} \times 10^{3}$ and morphological data are given in $\mathrm{mm} \times 10^{3}$
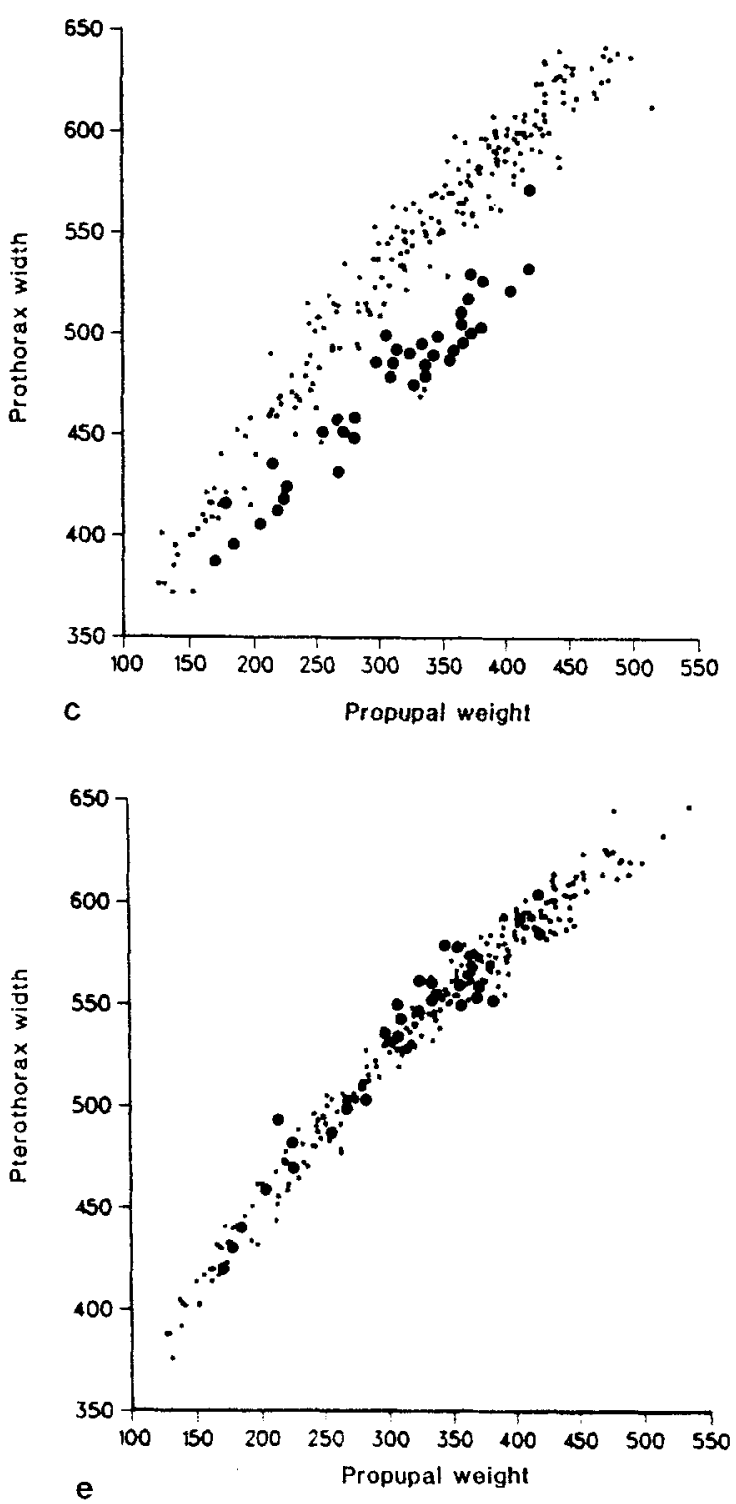


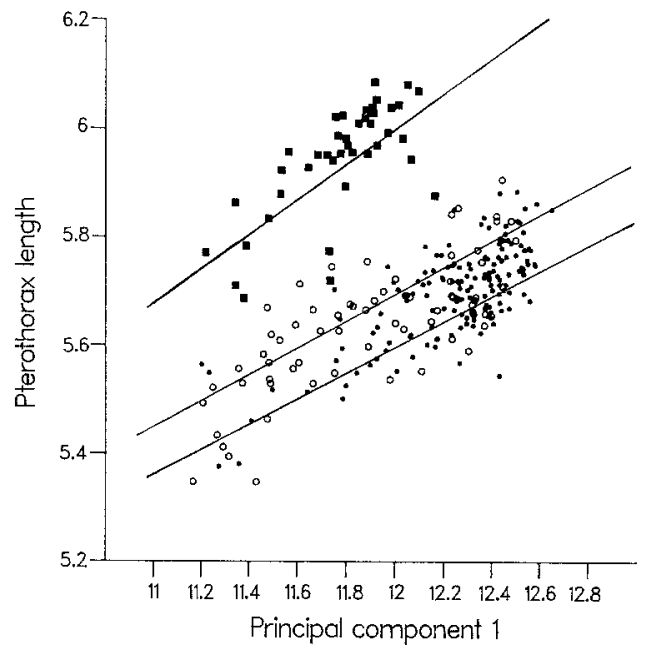

Fig. 2. Principal component 1 versus pterothorax length for winged males (squares), wingless males that developed in the treatment (L25) that produced a high proportion of winged males (open circles), and other wingless males (CON, L12, L15, and L22) (closed circles). The regressions differed for winged males $\left(y=0.33 \mathrm{x}+2.05, r^{2}=0.51, n=41\right)$, wingless males in the L25 treatment $\left(y=0.23 x+2.93, r^{2}=0.57, n=68\right)$, and other wingless males $\left(y=0.23+2.83, r^{2}=0.53, n=158\right)$. Wingless L25 males had size-adjusted pterothorax lengths intermediate between those of winged males and other wingless males

$(3.44 \pm 0.06, n=158)(t=3.13, P=0.0019)$, comparing the two categories of wingless male. The covariance analysis is illustrated in Fig. 2. The regressions for the three categories of male did not differ in slope $\left(F_{2,261}=2.09, P>0.10\right)$, but varied significantly in elevation $\left(F_{2,263}=399.8, \quad P<\right.$ $0.001)$; wingless L25 males were intermediate in size-adjusted pterothorax length (adjusted mean $=$ $5.686 \pm 0.071)$ between winged males $(6.021 \pm$ $0.073)$ and other wingless males $(5.659 \pm 0.073)$ $(t=2.42, P=0.016$, comparing the two categories of wingless male). Males in the CON, L12, L15, and L22 groups were not heterogeneous for either sheared $\mathrm{PC} 2$ score in the ANOVA or elevation in the ANCOVA $(P>0.05$ for all pairwise comparisons by $t$-tests); this justifies pooling them in the analysis. Thus, wingless L25 males were intermediate in overall body shape between winged males and other wingless males, and had relatively large pterothoraces with respect to other wingless males.

\section{Morphometric analysis of field-collected males}

For wingless males, the ranges of variation and the standard deviations of the five morphological characters were similar in field-collected males and in males that developed in this experiment (Table 5). However, for winged males, the amount of variation in the characters was somewhat lower
Table 5. The ranges and standard deviations of the five characters, for laboratory wingless males $(n=226)$, laboratory winged males $(n=41)$, field-collected wingless males $(n=24)$, and fieldcollected winged males $(n=14)$. Data for the field-collected males are in parentheses

\begin{tabular}{lccccc}
\hline \multirow{2}{*}{ Character } & \multicolumn{2}{l}{ Wingless males } & & \multicolumn{2}{l}{ Winged males } \\
\cline { 2 - 3 } \cline { 6 - 7 } & Range & SD & & Range & SD \\
\hline Fore-femoral & $0.244-0.618$ & 0.096 & $0.235-0.443$ & 0.047 \\
length & $(0.270-0.594)$ & $(0.098)$ & & $(0.251-0.376)$ & $(0.036)$ \\
Prothorax & $0.210-0.473$ & 0.062 & $0.203-0.362$ & 0.035 \\
length & $(0.175-0.468)$ & $(0.080)$ & & $(0.161-0.225)$ & $(0.019)$ \\
Prothorax & $0.372-0.665$ & 0.070 & & $0.388-0.572$ & 0.041 \\
width & $(0.408-0.694)$ & $(0.084)$ & & $(0.410-0.519)$ & $(0.037)$ \\
Pterothorax & $0.210-0.368$ & 0.029 & $0.295-0.440$ & 0.038 \\
length & $(0.230-0.334)$ & $(0.029)$ & & $(0.315-0.380)$ & $(0.022)$ \\
Pterothorax & $0.376-0.654$ & 0.063 & $0.421-0.604$ & 0.046 \\
width & $(0.424-0.678)$ & $(0.076)$ & $(0.435-0.547)$ & $(0.036)$ \\
\hline
\end{tabular}

for field-collected males than for experimental males, perhaps because only 14 field-collected males were measured.

For field-collected males, PC1 accounts for $97 \%$ of the variance and represents a general size factor with loadings similar to those of experimental males (Table 4). Sheared PC2 accounts for $2 \%$ of the variance and again represents a shape factor, or contrast between characters associated with fighting and dispersal, as in the analysis of experimental males. PC1 may explain proportionally more variance for the field males than for the laboratory males because the field males developed under similar conditions on the same log. The loading of prothorax width on sheared PC2 differed somewhat between analyses, for unknown reasons. Overall, these data show that the variation and covariation patterns of the five morphological characters are similar in the experimental and fieldcollected males.

\section{Variation in developmental time}

The duration of the larval and pupal instars varied between wing morphs and among treatments. Males that developed wings spent on average $29 \mathrm{~h}$ longer from hatching to adulthood $(749 \pm 68 \mathrm{~h}, n=$ 226), than did wingless males $(720 \pm 57 \mathrm{~h}, n=41$; Mann-Whitney $U$-test, $P<0.01$ ). This difference resulted from the relatively long duration of the propupal and pupal stages in males that developed wings (each of these three instars was $5-7 \mathrm{~h}$ longer; $P<0.05$ for each, Mann-Whitney $U$-tests). Neither of the larval instar durations differed significantly between wing morphs $(P>0.05$, Mann-Whitney $U$ - 
tests). Wingless males did not vary among food deprivation treatments in total developmental time or in duration of the second larval, propupal, or pupal instars (Kruskal-Wallis tests, $P>0.10$ ). However, wingless males in the L12 and L15 treatments spent longer in the first instar (L12: $253 \pm 38 \mathrm{~h}$; L15: $261 \pm 62 \mathrm{~h}$ ) than did wingless control males $(237 \pm 32 \mathrm{~h})$, wingless L22 males $(229 \pm 38 \mathrm{~h})$ or wingless L25 males $(237 \pm 36 \mathrm{~h})$ (Kruskal-Wallis test, $W=13.5, P<0.01$ ).

Total developmental time (from hatching to the adult molt) was not correlated with propupal weight or the five adult morphological characters in wingless males $(n=221)$ or winged males $(n=40)$ (Spearman's rho, $r<0.10, P>0.05$ for each). However, among winged males, duration of the propupal instar was positively correlated with prothorax width $(r=0.38, P<0.05)$ and pterothorax width $(r=0.37, P<0.05)$, and pterothorax length was negatively correlated with the duration of the first pupal instar $(r=-0.41, P<0.05)$. By contrast, among wingless males, propupal weight was positively correlated with duration of the second pupal instar $(r=0.19, P<0.05)$, and negatively correlated with duration of the second larval instar $(r=-$ $0.14, P<0.05$ ). In addition, wingless males exhibited significant negative correlations of the duration of the second larval instar with prothorax length $(r=-0.13, P<0.05)$ and with pterothorax width $(r=-0.15, P<0.05)$, and duration of the second pupal instar was positively correlated with each of the five morphological characters $(r>0.15$, $P<0.05$ for each).

The effects of the experimental treatments on the relationship between developmental time and morphology were investigated by examining the correlations for two categories of wingless male: those that were not affected morphologically by the treatments (CON, L12, L15, L22) $(n=155$ males with complete data) and those that developed under the conditions that produced winged males (L25) ( $n=66$ male with complete data). For males in the former (unaffected) treatments, propupal weight and all morphological characters except fore-femoral length were positively correlated with the duration of the second pupal instar (Spearman's rho, $r=0.17$ to $0.21, P<0.05$ for each), and were uncorrelated with duration of the second larval instar $(r=-0.09$ to $-0.15, P>0.05$ for each). Males in the L25 treatment exhibited the opposite trend: propupal weight and morphological characters were uncorrelated with the duration of the second pupal instar $(r=0.03$ to 0.12 , $P>0.05$ for each), and were negatively correlated with the duration of the second larval instar $(r=-$
0.26 to $-0.31, P<0.05$ for each). Thus, in the $\mathrm{L} 25$ treatment, males that became smaller adults spent a longer time in the second instar.

\section{Variation in male fighting success}

Winged and wingless males that interacted were within an average of $0.060 \pm 0.052 \mathrm{mg}$ in propupal weight, which comprised $23 \%$ of the total range of male propupal weight in this experiment. Winged males were heavier than wingless males as propupae in four interactions, wingless males were heavier in two interactions, and the males were nearly identical in propupal weight in four interactions. Wingless males became dominant over winged males in all ten of the interactions (Binomial test, $P<0.01$ ). Observation of male behavior showed that both wingless and winged males mated with females soon after the males were put into the colonies, but that wingless males won the fights that occurred, and winged males subsequently avoided contact with their opponents.

\section{Discussion}

The rearing experiments demonstrate that wing polymorphism and body size in male Hoplothrips karnyi are influenced by feeding conditions that larvae experience during the latter half of the second instar. This finding is consistent with the casual observations of previous authors that variation in fungus quality affects wing morph determination and body size in mycophagous thrips (Hood 1935, 1940; Bournier 1961; Mound 1972, 1976). Thus, in $H$. karnyi colonies, which commonly undergo more than one generation on a log, wingless males apparently develop under favorable conditions when the fungus is growing, whereas winged males develop when conditions deteriorate, favoring dispersal to new habitats. The timing of the cue, during the latter half of the second larval instar, allows morph determination to occur close in time to the conditions that males will experience as adults. However, the low proportion of males developing wings in this experiment suggests that other factors are also be involved in morph determination. In particular, experiments in which the offspring of one or two foundress females were reared together showed that the proportion of males that developed wings was also associated with the density of developing offspring; overall, $37 \%$ of the variation in proportion winged was explained by variation in density (Crespi 1987). If high density does not engender deterioration of ecological conditions, then feeding conditions and 
larval density may jointly affect morph determination.

Close correspondence between the nature and timing of wing morph determination cues and the costs and benefits of dispersal have been found in a variety of insects (Harrison 1980; Zera et al. 1983; Roff 1986a). However, few studies have been conducted on the developmental basis of male polymorphism. In the earwig Forficula auricularia, which exhibits a dimorphism in male cerci size that may be associated with male fighting, Kuhl (1928) found that food intake affects cerci size: starved nymphs developed into the morph with short cerci whereas well-fed nymphs developed long cerci (Diakonov 1925; Huxley 1927). In some mites in the genus Sancassania, males with an enlarged, armed pair of legs kill males of the unarmed morph and newly eclosed males of the armed morph (Woodring 1969; Timms et al. $1981 \mathrm{a}, \mathrm{b}$ ). The dimorphism is not heritable, and armed males develop at low population densities. In a male-dimorphic horned beetle, males with small horns emerge relatively early and disperse more widely, apparently to avoid competition with their largehorned rivals (Eberhard 1982); in this and other beetles, body size and morph are probably influenced by larval nutrition (e.g., Eberhard 1982; Goldsmith 1987). Data from these species support the hypothesis that male polymorphisms are cued primarily by environmental factors associated with predictable variation in the costs and benefits of engaging in or avoiding male fighting (Hamilton 1979).

In Hoplothrips karnyi, the behavioral correlates of male polymorphism are fighting and dispersal ability: wingless males are superior fighters, but cannot disperse. The finding that, for a given propupal weight, wingless males have larger fore-femora and prothoraces and smaller pterothoraces than winged males indicates that this behavioral variation reflects a morphological trade-off between characters associated with fighting and dispersal ability. The cost of wings in terms of forefemoral and prothoracic size, or the magnitude of the trade-off, increases asymtotically with propupal weight; thus for heavier males the expected decrease in fore-femoral length and prothorax size with the development of wings is relatively large (see also Huxley 1932). An alternative explanation for the observed patterns is that winged males with large forelegs would be inefficient at dispersal. However, the existence of many thrips species with only winged males and greatly enlarged forelegs (Stannard 1968; Ananthakrishnan 1984) argues against this hypothesis.
Recent discussions of alternative male morphology and mating behavior have focused on demonstrating the adaptive significance of the alternative tactics (Thornhill and Alcock 1983). This approach has been considered controversial because the extent to which phenotypic variation represents adaptation, as opposed to compromise, constraint, or maladaptation, is not clear (Gould and Lewontin 1979; Wade 1984). The results of this study suggest that Hoplothrips karnyi wing morph determination represents an adaptive conditional response to environmental variation involving a trade-off between fighting and dispersal ability. However, the existence of relatively small wingless males in the field and laboratory remains problematic, because these males are inferior fighters and would pay a relatively low cost, in terms of forelegs and the prothorax, were they to develop wings. Thus, it is unclear why $H$. karnyi males do not exhibit two distinct morphs, large fighters and smaller fliers. Moreover, the shape intermediacy of wingless males that developed in the treatment that produced a high proportion of winged males (L25) suggests that the switch between wing morphs is subject to developmental constraints, defined as "biases in the production of variant phenotypes ... caused by the structure, character, composition or dynamics of the developmental system" (Maynard Smith et al. 1985).

The morphometric and developmental time data suggest that the development of small wingless males involves a compromise between the benefits of large adult size and the costs of prolonging development to increase the probability of becoming larger. As discussed above, winged males, because of their small foreleg size, effectively opt out of male-male competition for egg mass areas. Thus, if the potential fitness benefits of being large and wingless sufficiently exceed, under most circumstances, the potential fitness benefits of becoming winged, then males may be more likely a priori to become wingless, even if such a tactic sometimes leads to small body size and inability to disperse. This hypothesis is consistent with the negative correlation of propupal weight and adult morphological characters with duration of the second larval instar among L25 males, because prolongation of this instar may allow males to resume feeding and grow larger should conditions improve (see also Scriber and Slansky 1981; Sigurjonsdottir 1984; Forrest 1987). Presumably, at some point the cost of prolonging the second instar, perhaps in terms of increased mortality, becomes prohibitively large. Mortality late during development may also select for winglessness, because of the increased 
duration of the propupal and pupal instars in winged males. This hypothesis does not explain why small wingless males do not prolong development for a period of time and then become winged if conditions remain poor. However, this argument assumes that males assess accurately their expected adult body size as larvae; to the extent that any uncertainty exists with regard to a male's size, becoming wingless may be advantageous, because of the cost, in terms of weaponry, of developing wings. Alternatively, there may be unmeasured advantages to winglessness for small males, such as high survivorship or high sperm production relative to males that develop wings.

The shape intermediacy of wingless males that developed in the treatment (L25) that produced a high proportion of winged males may also represent a compromise between developmental timing and adult phenotype; as Harrison (1980) noted, "decisions made late in development allow a more flexible response but may involve a greater cost (e.g., development of unnecessary structures)." Thus, for wingless males, the benefits of being able to switch morphs late in development may outweigh the costs of developing, under certain circumstances, an "unnecessarily" large pterothorax. If L25 males were near the switch point between morphs, and were inadequately canalized (Waddington 1957) in their development to develop pterothoraces of the "appropriate" relative size for wingless males, then this shape intermediacy may be regarded as an expression of a developmental constraint on the adult phenotype (Maynard Smith et al. 1985). In thrips, developmental constraints may be associated speculatively with their apparent independent evolution of holometaboly, with larval instars being converted to pupal stages (Snodgrass 1954; Heming 1970), or the evolutionarily recent addition of the first pupal stage in tubuliferan thrips (Heming 1973).

To understand more fully the relative contributions of natural selection, compromise, and constraints to Hoplothrips karnyi male phenotypes, further research is needed on the genetic, physiological, and environmental basis of wing morph and body size and shape determination, and on the development and morphometrics of other Hoplothrips species that differ in body size and wing polymorphism patterns. However, the data presented here indicate that constraints and compromises may sometimes be involved in the evolution of alternative male tactics. For wing polymorphism and male dimorphism, developmental constraints and selective compromises may entail either restrictions on the origin of new morphs, or, as may be true in $H$. karnyi, biases in the range of variation produced. Consideration of hypotheses based on constraint and compromise is important to a thorough understanding of the adaptive and non-adaptive significance of phenotypic variability.

Acknowledgements. I would like to thank R.D. Alexander, J. Dickinson, B. Heming, L.A. Mound, and B. OConnor for helpful comments on earlier versions of this manuscript, and F.L. Bookstein, W. Dominey, W.D. Hamilton, D. Roff, and R. Wrangham for valuable discussions. Thanks also to D. Goldberg, for instruction in use of the electrobalance, and to two anonymous reviewers, for many useful comments.

\section{References}

Ananthakrishnan TN (1967) Allomorphic growth patterns in some tubulifera (thrips). Indian J Entomol 29:61-64

Ananthakrishnan TN (1968) Allomorphic growth patterns in relation to sex-limited polymorphism in some mycophagous tubulifera (Thysanoptera). Curr Sci 37:573-578

Ananthakrishnan TN (1970) Trends in intraspecific sex-limited variation in some mycophagous tubulifera. J Bombay Nat Hist Soc 67:481-501

Ananthakrishnan TN (1979) Biosystematics of Thysanoptera. Ann Rev Entomol 24:159-183

Ananthakrishnan TN (1984) Bioecology of Thrips. Indira Publishing, Oak Park, Michigan

Barnard CJ (1984) Producers and scroungers: strategies of exploitation and parasitism. Chapman \& Hill, New York

Bookstein F, Chernoff B, Elder R, Humphries J, Smith G, Strauss $R$ (1985) Morphometrics in evolutionary biology. Phil Acad Nat Sci, Special Publication 15

Bournier A (1961) Remarques au sujet du brachypterisme chez certaines especes de Thysanopteres. Bull Soc Entomol Fr 66:188-191

Briceno RD, Eberhard WG (1987) Genetic and environmental effects on wing polymorphisms in two tropical earwigs (Dermaptera: Labiidae). Oecologia 74:253-255

Cade W (1980) Alternative male reproductive behaviors. Fla Entomol 63:38-44

Caro TM, Bateson P (1986) Organization and ontogeny of alternative tactics. Anim Behav 34:1483-1499

Clark WC (1976) The environment and the genotype in polymorphism. Zool J Linn Soc 58:255-262

Cowan DP (1984) Life history and male dimorphism in the mite Kennethiella trisetosa (Acarina: Winterschmitiidae), and its symbiotic relationship with the wasp Ancistrocerus antilope (Hymenoptera: Eumenidae). Ann Entomol Soc Am $77: 725-732$

Crespi BJ (1986a) Territorality and fighting in a colonial thrips, Hoplothrips pedicularius, and sexual dimorphism in Thysanoptera. Ecol Entomol 11:119-130

Crespi BJ (1986b) Size assessment and alternative fighting tactics in Elaphrothrips tuberculatus (Insecta: Thysanoptera). Anim Behav 34:1324-1335

Crespi BJ (1987) The behavioral ecology of mycophagous Thysanoptera. $\mathrm{PhD}$ thesis, University Michigan, Ann Arbor

Crespi BJ (1988) Risks and benefits of lethal male fighting in the colonial, polygynous thrips Hoplothrips karnyi (Insecta: Thysanoptera). Behav Ecol Sociobiol 22:293-301

Davies RG (1969) The skeletal musculature and its metamorphosis in Limothrips cerealium Haliday (Thysanoptera: 
Thripidae). Trans Royal Entomol Soc Lond 121:167233

Day MC (1984) Male polymorphism in some Old World species of Cryptocheilus Panzer (Hymenoptera: Pompilidae). Zool J Linn Soc 79:83-101

Diakonov DM (1925) Experimental and biometrical investigations on dimorphic variability of Forficula. J Genetics 15:201-232

Dominey WJ (1980) Female mimicry in male bluegill sunfish - a genetic polymorphism? Nature 284:546-548

Dominey WJ (1984) Alternative mating tactics and evolutionarily stable strategies. Am Zool 24:385-396

Eberhard WG (1980) Horned beetles. Sci Am 242:166-182

Eberhard WG (1982) Beetle horn dimorphism: making the best of a bad lot. Am Nat 119:428-426

Forrest TG (1987) Insect size tactics and developmental strategies. Oecologia 73:178-184

Goldsmith SK (1985) Male dimorphism in Dendrobias mandibularis Audinet-Serville (Coleoptera: Cerambycidae). J Kans Entomol Soc 58:534-538

Goldsmith SK (1987) The mating system and alternative reproductive behaviors of Dendrobias mandibularis (Coleoptera: Cerambycidae). Behav Ecol Sociobiol 20:111-115

Gould SJ, Lewontin RC (1979) The spandrals of San Marco and the Panglossian paradigm: A critique of the adaptationist programme. Proc Royal Soc Lond 205:581-598

Graves RC (1960) Ecological observations on the insects and other inhabitants of woody shelf fungi (Basidiomycetes: Polyporaceae) in the Chicago area. Ann Entomol Soc Am $53: 61-78$

Gross MR (1985) Disruptive selection for alternative life histories in salmon. Nature 313:47-48

Gupta AP (1979) Arthropod phylogeny. Litton Press, New York

Hamilton WD (1978) Evolution and diversity under bark. In: Mound LA, Waloff $\mathrm{N}$ (eds) Diversity of insect faunas Blackwell, London, pp 154-175

Hamilton WD (1979) Wingless and fighting males in fig wasps and other insects. In: Blum MS, Blum NA (eds) Sexual selection and reproductive competition in insects. Academic Press, New York, pp 167-220

Harrison RG (1980) Dispersal polymorphisms in insects. Ann Rev Ecol Syst 11:95-118

Heming BS (1970) Postembryonic development of the female reproductive system in Frankliniella fusca (Thripidae) and Haplothrips verbasci (Phlaeothripidae) (Thysanoptera). Misc Publ Am Entomol Soc 7:197-234

Heming BS (1973) Metamorphosis of the pretarsus in Frankliniella fusca (Hinds) (Thripidae) and Haplothrips verbasci (Osborn) (Phlaeothripidae) (Thysanoptera). Can J Zool 51:1211-1234

Heming BS (1975) Antennal structure and metamorphosis in Frankliniella fusca (Hinds) (Thripidae) and Haplothrips verbasci (Osborn) (Phlaeothripidae) (Thysanoptera). Quaest Entomol 11:25-68

Hood JD (1935) A note on heterogony in the Thysanoptera with descriptions of two new species from Tanganyika. Stylops 4:193-201

Hood JD (1937) Studies in Neotropical Thysanoptera IV. Rev de Entomol 7:495-507

Hood JD (1940) The cause and significance of macropterism and brachypterism in certain Thysanoptera with description of a new Mexican species. Anales de la Escuela National de Ciencas Biologicas 1:493-505

Houston TF (1970) Discovery of an apparent soldier caste in a nest of a halictine bee (Hymenoptera: Halictidac), with notes on the nest. Austral J Zool 18:345-351
Humphries JM, Bookstein FL, Chernoff B, Smith GR, Elder RL, Poss SG (1981) Multivariate discrimination by shape in relation to size. Syst Zool 30:291-308

Huxley JS (1927) Discontinuous variation and heterogony in Forficula. J Genetics 17:309-327

Huxley JS (1932) Problems of relative growth. Methuen, London

Huxley JS (1955) Morphism and evolution. Heredity 9:1-54

Jolicoeur P (1963) The multivariate generalization of the allometry equation. Biometrics 19:497-499

Kiester AR, Strates E (1984) Social behaviour in a thrips from Panama. J Nat Hist 18:303-314

Kinomura K, Yamauchi K (1987) Fighting and mating behaviors of dimorphic males in the ant Cardiocondyla wroughtoni. J Ethol 5:75-81

Kuhl W (1928) Die variabilitat der abdominal Korperanhange van Forficula auricularia L. Z Morph Oekol Tiere 12:299-532

Langor DW, Larson DJ (1983) Alary poymorphism and life history of a colonizing ground beetle Bembidion lampros Herbst (Coleoptera: Carabidae). Coleop Bull 37:365-377

Levins R (1968) Evolution in changing environments. Princeton University Press, Princeton, NJ

Lively CM (1986) Predator-induced shell dimorphism in the acorn barnacle Chthamalus anisopoma. Evolution $40: 232-242$

Mather K (1955) Polymorphism as the outcome of disruptive selection. Evolution 9:52-61

Maynard Smith J, Burian R, Kauffman S, Alberch P, Campbell J, Goodwin B, Lande R, Raup D, Wolpert L (1985) Development constraints and evolution. Q Rev Biol 60:265-287

Messina FJ (1987) Genetic contribution to the dispersal polymorphism of the cowpea weevil (Coleoptera: Bruchidae). Ann Entomol Soc Am 80:12-16

Mickoleit G (1961) Zur thoraxmorphologie der Thysanoptera. Zool Jb Anat Ontol Tiere 79:1-92

Mound LA (1970) Intragall variation in Brithothrips fuscus Moulton with notes on other Thysanoptera-induced galls from Acacia trees in Australia. Entomol Mon Mag 105:159-162

Mound LA (1972) Species complexes and the generic classification of leaf-litter thrips of the tribe Urothripini (Phlaeothripidae). Austral J Zool 20:83-103

Mound LA (1976) American leaf-litter thrips of the genera $\mathrm{Er}$ kosothrips, Eurythrips, and Terthothrips. Bull Br Mus Nat Hist (Entomol) 35:27-64

Priesner H (1960) A monograph of the Thysanoptera of the Egyptian deserts. Publ Inst Desert Egypt 13:1-549

Ritchie MG, Butlin RK, Hewitt GM (1987) Causation, fitness effects and morphology of macropterism in Chorthippus parallelus (Orthoptera: Acrididae). Ecol Entomol 12:209-218

Roff DA (1986a) The evolution of wing dimorphism in insects. Evolution 40:1009-1020

Roff DA (1986b) The genetic basis of wing dimorphism in the sand cricket, Gryllus firmus and its relevance to the evolution of wing dimorphisms in insects. Heredity 57:221231

Scriber JM, Slansky F Jr (1981) The nutritional ecology of immature insects. Ann Rev Entomol 26:183-211

Shillito JF (1971) Dimorphism in flies with stalked eyes. Zool J Linn Soc 50:297-305

Sigurjonsdottir H (1984) Food competition among Scatophaga stercoraria larvae with emphasis on its effects on reproductice success. Ecol Entomol 9:81-90

Siva-Jothy MT (1987) Mate securing tactics and the cost of fighting in the Japanese horned beetle, Allomyrina dichotoma L. (Scarabaeidae). J Ethol 5:165-172 
Snodgrass RE (1954) Insect metamorphosis. Smithson Misc Collect 122:1-124

Solbreck C (1986) Wing and flight muscle polymorphism in a lygaeid bug, Horvathiolus gibbicollis: determinants and life history consequences. Ecol Entomol 11:435-444

Stannard LJ (1957) The phylogeny and classification of the North American genera of the suborder Tubulifera. Ill Biol Monogr 25. University of Tllinois Press, Urbana

Stannard LJ (1968) The thrips, or Thysanoptera of Illinois. Bull Ill Nat Hist Surv 29:215-552

Taylor VA (1978) A winged elite as a model for a prototermite. Nature 276:73-74

Taylor VA (1981) The adaptive and evolutionary significance of wing polymorphism and parthenogenesis in Ptinella Motschulsky (Coleoptera: Ptiliidae). Ecol Entomol 6:8998

Thornhill R, Alcock J (1983) The evolution of insect mating systems. Harvard University Press, Cambridge

Timms S, Ferro DN, Emberson RM (1981 a) Andropolymorphism and its heritability in Sancassania berlesei (Michael) (Acari: Acaridae). Acarologia 22:391-398

Timms S, Ferro DN, Emberson RM (1981 b) Selective advan- tage of polymorphic male Sancassania berlesei (Michael) (Acari: Acaridac). Int J Acarol 6:97-102

Waddington C (1957) The strategy of the genes. Allen \& Unwin, London

Wade MJ (1984) The evolution of insect mating systems. Evolution 38:706-708

West-Eberhard MJ (1983) Sexual selection, social competition, and speciation. Q Rev Biol 58:155-183

Wright S (1968) Evolution and the genetics of populations. Vol. 1. genetic and biometric foundations. University of Chicago Press, Chicago, Ill

Woodring JP (1969) Environmental regulation of andropolymorphism in Tyroglyphids (Acari). In: Evans GO (ed) Proceedings of the 2nd International Congress of Acarology. Akademiai kiado, Budapest, pp 431-440

Zera AJ (1984) Differences in survivorship, development rate and fecundity between the longwinged and wingless morphs of the waterstrider, Limnoporous canaliculatus. Evolution $38: 1023-1032$

Zera AJ, Innes DI, Saks ME (1983) Genetic and environmental determinants of wing polymorphism in the waterstrider, Limnoporous canaliculatus. Evolution 37:513-522 